\title{
Towards a definition of SUBJECT in binding domains and subject oriented anaphors ${ }^{1}$
}

\author{
Mark de Vos \\ Department of English Language and Linguistics, Rhodes University, 6140 Grahamstown \\ E-mail: m.devos@ru.ac.za
}

\section{Introduction}

This paper is concerned with the notion of SUBJECT and with providing a definition couched in Minimalist terms. The question of subjecthood has long been an area of serious debate. In current versions of Minimalism, subjects do not have primitive status and can only be defined in derived terms. However, subjects and the broader theoretical notion of SUBJECT remain important in linguistic description. This paper develops a definition of subjecthood in terms of set-theoretic notions of functional dependency: when a feature, say $\phi$, determines the value of some other feature, say $u \phi$. This notion is used to describe various phenomena where subjecthood has been invoked, namely binding domains and subject-oriented anaphors.

\section{The problem of subjects}

SUBJECTs are indispensable for Binding Theory, as given in (1), where they define domains for anaphors and pronouns (Chomsky 1981).

(1) a. i. Principle A: An anaphor must be bound within its governing category. ii. Principle B: A pronominal must be free within its governing category. 
iii. Principle C: An R-expression must be free (Chomsky 1981).

b. B is a governing category for A if and only if B is the minimal category containing A, a governor of A, and a SUBJECT accessible to A (Chomsky 1981).

In the remainder of this paper, I will use the neutral term "binding domain" rather than "governing category" for two reasons. First, the technical term of "governing category" is no longer operative in Minimalist syntax. However, it is worth noting that a fully fledged binding theory is still lacking in the Minimalist programme. As such, it is still necessary to invoke older, pre-Minimalist notions in order to discuss binding phenomena. The second reason is that "governing category" only refers to the domain in which reciprocals and local, Englishtype himself anaphors are bound - it does not include the larger domain characteristic of subject-oriented anaphora (cf. section 6). Consequently, I will use the more theoretically neutral term "binding domain" for the remainder of this paper. I take the two terms to be broadly equivalent (although I redefine the notion of 'binding domain' in (13)). It is hoped that one of the contributions of this paper will be to provide a framework from which a Minimalist notion of 'binding domain' can be developed in future research.

The pair of examples in (2) shows that anaphors must be bound, and that pronouns must be free, within a domain delimited by a subject.

a. The twins $s_{i}$ said that $\|_{\text {Sub }}$ he liked $*$ each other ${ }_{i} /$ them $_{i}$

b. He said that $\|_{\text {Sub }}$ the twins $\mathrm{i}_{\mathrm{i}}$ liked each other $\mathrm{i} / *$ them $_{\mathrm{i}}$

The paradigm can be extended to binding within DPs. A possessor defines a binding domain. When the possessor is present ( $3 \mathrm{a}$ ) then the anaphor must be bound within the DP - and the pronoun must be free within the DP. When the possessor is absent (3b), then the anaphor must be bound in the domain defined by the clausal subject - and the pronoun must be free in this domain.
a. The twins $\mathrm{i}_{\mathrm{i}}$ liked [ $\|_{\text {Sub }}$ John's pictures of $*$ each other $\mathrm{i}_{\mathrm{i}} /$ them $\left._{\mathrm{i}}\right]$
b. The twins ${ }_{\mathrm{i}}$ took $\left[\|_{\text {Sub }} \varnothing \quad\right.$ pictures of each other $\mathrm{r}_{\mathrm{i}} / *$ them $\left._{\mathrm{i}}\right]$

Thus, the possessor counts as a SUBJECT as far as the Binding Theory is concerned. 


\section{The difficulty of defining subjecthood}

The problem with using SUBJECT as a primitive of the Binding Theory is that it is difficult to adequately define - a problem that stems from the difficulty of defining subjecthood more generally. ${ }^{2}$ Although subjecthood is an essential descriptive device in linguistics, it is not clear from what it is derived at a theoretical level. Over the years, various prototypical, nonexclusive properties of subjects have been proposed. None are either necessary or sufficient. A non-exhaustive list that illustrates the extent of the problem is given in (4).

(4) Subjects may: a. be involved in predication

b. be agents

c. determine agreement on a predicate

d. be located in SpecTP

e. have nominative case

f. be linked to EPP phenomena

g. be the highest argument of a VP

(i.e. there is only one of them, it will typically precede other arguments etc.)

h. be antecedents for subject-oriented anaphors (e.g. Maling 1984)

However, none of these diagnostics appear to be necessary or sufficient - there are putative counter examples to all of them.

One of the oldest notions of subjecthood was its link to predication. However, not all predication structures are domains for Binding Theory. Example (5) contains a small clause predication structure. The anaphor can be bound by the clausal subject, i.e. the subject of the small clause predicate does not appear to be a domain for binding.

(5) Dr. Robert Bruce Banner ${ }_{i}$ considered [sc the Incredible Hulk (to be) a clone of himself $\left._{\mathrm{i}} / * \operatorname{him}_{\mathrm{i}}\right]^{3}$

Similarly, subjects also cannot be defined in purely semantic terms. Although subjects are often agents, there are examples where they are not. In many Bantu languages, a semantic 
object may occur in subject position and determine agreement. Also, in the following English passive sentence, the subject is a Theme.

\section{(6) A cat was seen}

The agreement diagnostic raises the question of agreeing objects in languages with object agreement (e.g. many Bantu languages) and the DPs associated with postpositions, etc. The agreement diagnostic also suggests that, in example (7), the DP a cat is the subject, raising questions about the status of the expletive there. I will return to the agreement diagnostic; this paper will show that agreement is a crucial indicator of SUBJECT - although agreement itself is not the crucial factor - it is only indicative of it.

\section{(7) There is a cat at the door}

A related diagnostic is that the subject be located in SpecTP (i.e. the Extended Projection Principle (EPP) holds). However, this is also problematic, as the previous example demonstrates: an expletive is in SpecTP (an indicator of subjecthood), whereas agreement is determined by the indefinite DP (also an indicator of subjecthood). ${ }^{4}$

The Case diagnostic can also lead to confusing results. In some languages (e.g. Korean), there can be more than one nominative DP in a clause. In languages with quirky case (e.g. Icelandic), a DP (which otherwise conforms with other properties of subjects) may be marked with dative, or a default case other than nominative. In addition, the possessor in (3) has genitive case, not nominative.

Another property is that the subject is the highest argument of a VP. However, if nominative Case defines subjecthood, then this cannot be true in multiple nominative constructions (e.g. Korean). More often than not, the subjecthood of the highest argument is stipulated (e.g. in the argument list (HPSG, LFG)) - in other words, it is a theory-internal assumption.

A related issue is the EPP, which ensures that every clause has a subject. However, there is as yet no consensus on what the EPP is or even whether it exists (Martin 1999; Boeckx 2000a), 
and it holds little explanatory value. At best, EPP ensures that the highest argument will move to subject position.

The final property I will discuss here is the fact that, in some languages (e.g. Icelandic and Dutch), there is a subset of anaphors which can only be bound by subjects. Whereas this has been used as a diagnostic for subjecthood (e.g. Maling 1984; Zaenen, Maling, and Thráinsson 1985), it is unclear what actually determines this binding behaviour, or why subjects should be the sole antecedents for some anaphors but not others. The upshot is that this phenomenon is a diagnostic, and is defined in a circular manner: a subject-oriented anaphor is bound by a subject - a subject can be an antecedent for a subject-oriented anaphor.

To summarize, although SUBJECT is important for the Binding Theory, it is not clear how SUBJECT is related to subjecthood more generally, or even what subjecthood reduces to at a theoretical level. In some frameworks, such as LFG, Relational Grammar, and HPSG, subjecthood is stipulated. In the frameworks of Principles and Parameters and the Minimalist Program, on the other hand, there has been a sustained attempt to sidestep the problem of subjecthood by deriving it from more fundamental properties. In this venture, I think that these frameworks have been largely successful, although significant problems remain. For instance, many properties of subjects are derived from an interaction of locality constraints on movement (thus the DP that moves to Spec TP will always be the highest DP in the VP, etc.). Similarly, nominative case is regarded as a reflex of Tense (Pesetsky and Torrego 2001). This paper continues the tradition by proposing a theoretical basis for SUBJECT flowing from relational theory (Codd 1970). The advantage of this approach is that it provides a principled manner of choosing between the various empirically based means of defining subject (e.g. in terms of agreement, nominative case, etc). While much of the data I will discuss in this paper relates to agreement, this by itself is not superior to notions of SUBJECT defined in terms of nominative case or any of the other possible characteristics of subjects. However, if it can be shown that agreement is underpinned by a theoretically primitive relation, this would lend credence to definitions of subjecthood which draw on agreement phenomena. 


\section{Basic assumptions}

The present paper is based on a number of central assumptions, outlined in 4.1 to 4.5 below. The proposal is broadly couched within the Minimalist Program (Chomsky 1995a and subsequent works), although some of the conclusions may diverge from some of the later versions of this framework.

\subsection{AGREE}

AGREE is asymmetric (Chomsky 1995a: 277-279). Pairs of uninterpretable and interpretable features are mediated by AGREE, a pairwise relationship between a PROBE and a GOAL, where uninterpretable features on the PROBE are valued by the equivalent interpretable features on the GOAL (Chomsky 2000), yielding an ordered pair (GOAL, PROBE). In other words, the value of the GOAL, e.g. $\phi$, determines the value of the PROBE $u \phi$. With respect to Case features, I assume that nominative case is a manifestation of uT on nominals checked by the corresponding T feature on the tense head (Pesetsky and Torrego 2001).

\subsection{Anaphors}

Since a large part of this paper will constitute a discussion of anaphors, I will outline some basic assumptions here. As there is no equivalent of binding within the Minimalist Program (Chomsky 1995a), I assume, as a starting point, traditional Binding Theory (Chomsky 1981), and specifically, principles A and B and the notion of governing category, as in (1).

Concerning the feature specification of anaphors themselves, anaphors are traditionally specified as [+ANAPHORIC], a feature taken to be mnemonic for the referential defectiveness of the anaphor (Chomsky 1981; Reinhart and Reuland 1991; Thráinsson 1991). I take anaphors to lack (a subset of) appropriate $\phi$ features; $\phi$ features, and ultimately referentiality, are supplied by the antecedent mediated by a command relation. ${ }^{5}$

\subsection{Phrase structure}

Concerning phrase structure, I start from the proposition that A merged with $\mathrm{B}$ yields a partially ordered set $\{A,\{A, B\}\}$ (Chomsky 1995b). In particular, I assume that such a structure is unambiguous and can represent a single relationship. In (8), it is A that selects B - 
B cannot simultaneously select A: phrase structure is unambiguous (Devlin 1993; Halmos 1960). ${ }^{6}$

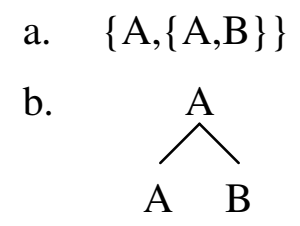

\subsection{Functional dependencies}

Furthermore, I would like to introduce a useful tool, namely the notion of 'functional dependency'. The notation $\{$ A, $\{$ A,B $\}\}$ used to represent phrase structure (Chomsky 1995b) is not only a convenient way of representing linguistic trees. Mathematically speaking, this notation actually means something; A and B are (partially) ordered, where A determines some property of $\mathrm{B}-\mathrm{a}$ functional dependency.

Functional dependencies are useful because they provide an intuitive manner of relating to phrase structure. Functional dependencies constitute a theoretical notion which I borrow from Relational Theory (Codd 1970), a branch of set-theoretic mathematics. Drawing on the definition of functional dependencies provided by Dutka and Hanson (1989), I define functional dependencies in syntactic terms in (9) (De Vos 2006a,b). In the remainder of this paper, I will use arrows to indicate functional dependency, as is standard in the literature on the topic.

(9) a. Functional dependency: Let $\mathrm{X}$ and $\mathrm{Y}$ represent sets of syntactic features (trivially including sets of just one feature). $\mathrm{X}$ functionally determines $\mathrm{Y}$ if the value of $X$ determines the value of Y (i.e. $X \rightarrow$ Y) $\left(\right.$ De Vos 2006a,b). ${ }^{7}$

b. Value: Let the value of $\mathrm{X}$ and $\mathrm{Y}$ be the value of features (eg. categorial features $\pm \mathrm{N}, \pm \mathrm{V}$; formal features $u \phi$, $\phi$, semantic features \pm AGENT etc.).

c. Transitivity: Functional dependencies are transitive. If $\mathrm{X} \rightarrow \mathrm{Y}$ and $\mathrm{Y} \rightarrow \mathrm{Z}$, then $X \rightarrow Z$ (Armstrong 1974; Beeri, Fagan, and Howard 1977; Sagiv, Delobel, Stott Parker, and Fagin 1981). 
Intuitively, this means that if $\mathrm{X}$ selects a complement $\mathrm{Y}$, then $\mathrm{X}$ functionally determines $\mathrm{Y}$, i.e. $\mathrm{X} \rightarrow \mathrm{Y}$. Similarly, if $\mathrm{W}$ agrees with $\mathrm{Z}$, then the feature value of $\mathrm{W}$ (e.g. 3SG) is determined by the properties of $\mathrm{Z}$ (e.g. 3SG), i.e. $\mathrm{Z} \rightarrow \mathrm{W}$. I take it as a fundamental fact that phrase structure can be expressed in terms of functional dependencies. ${ }^{8}$ It is important to note that functional dependencies and their properties, including transitivity, are not contentious within Relational Theory. The only novelty about the current approach is that I propose to apply functional dependency to syntactic relationships, in particular to agreement and selection, although this is not an exclusive listing.

(10) Agreement and selection are functional dependencies

a. A feature $\mathrm{F}$ determines the value of a corresponding $\mathrm{uF}$ feature; by examining the value of $\mathrm{F}$ alone (e.g. 3SG), one can determine the value of the uF (e.g. 3sG etc.): $\mathrm{F} \rightarrow \mathrm{uF}$.

b. A SUBCAT feature determines the value of the complement which it selects; by examining the SUBCAT feature alone, one can determine the value of the complement it selects.

\subsection{Projection and specifiers}

As SpecTP will figure prominently in the present discussion, it is worth mentioning some of the implications of the above assumptions for this position.

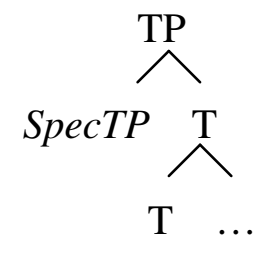

Given the assumptions outlined in the previous section, the fact that $\mathrm{T}(\mathrm{P})$ projects in $(11)$ is a function of the fact that $\mathrm{T}$ functionally determines features on the subject, namely Case, not to mention the fact that $\mathrm{T}$ also selects for a subject as a function of the EPP.

However, the subject also agrees with $u \phi$ on $\mathrm{T}$, and thus the subject functionally determines these features on $\mathrm{T}$ by AGREE. As pointed out by an anonymous reviewer, this may be taken to 
imply that SpecTP selects T, because $\phi$ features on the DP in SpecTP determine uninterpretable features on $\mathrm{T}$, a conclusion seemingly at odds with standard phrase structure. In fact, this is only an apparent problem. While every selection relation is also a functional dependency, it is not the case that every functional dependency is a selectional relationship. AGREE holds when a value on a GOAL feature determines the value on a PROBE feature. Thus, the $\phi$ features on the DP in SpecTP AGREE with their uninterpretable counterparts on T; this constitutes a functional dependency, but it does not imply that the DP as a whole "selects" T. It merely entails that some feature in the DP feature bundle functionally determines some corresponding feature in the T feature bundle. ${ }^{9}$

To summarize, this section has proposed that syntactic relations such as selection and AGREE can be represented by functional dependencies, a basic relationship derived from Relational Theory and Set Theory. In addition to their mathematical grounding independent of linguistic theory, functional dependencies are not actually an assumption per se - rather, functional dependencies are a natural consequence of a set-theoretic approach to phrase structure (Chomsky 1995b). Functional dependencies must therefore be regarded as a deep property of linguistic theory. ${ }^{10}$

\section{Arguments in favour of a functional dependency approach to binding domains}

There are three main arguments for a functional dependency approach to binding domains. The first argument, set out in the previous section, is theoretical - functional dependencies follow from standard assumptions about phrase structure and syntactic relationships; if Chomsky (1995a) is taken as a starting point, then functional dependencies are necessarily inherent in linguistic structures. The second argument is based on the fact that functional dependencies provide a way of distinguishing subjects from non-subjects - a distinction that has remained important in linguistics despite its resistance to formalization. The third argument for functional dependencies is that they allow the integration of possessive and clausal subjects under a single banner.

\subsection{Functional dependencies distinguish subjects from non-subjects}

The usefulness of functional dependencies is that they can be used to distinguish subjects from non-subjects. At the heart of this idea is the notion that agreement can instantiate a 
functional dependency, as explained in the previous section. Consider the relationships present in the LF representation in (12). I will assume a $v \mathrm{P}$ shell structure where light verbs introduce verbal arguments and where V-v raising takes place (Larson 1988). The subject DP has moved from SpecvP to SpecTP. ${ }^{11}$

(12) a. Sarah gave the ball to Susan

b.

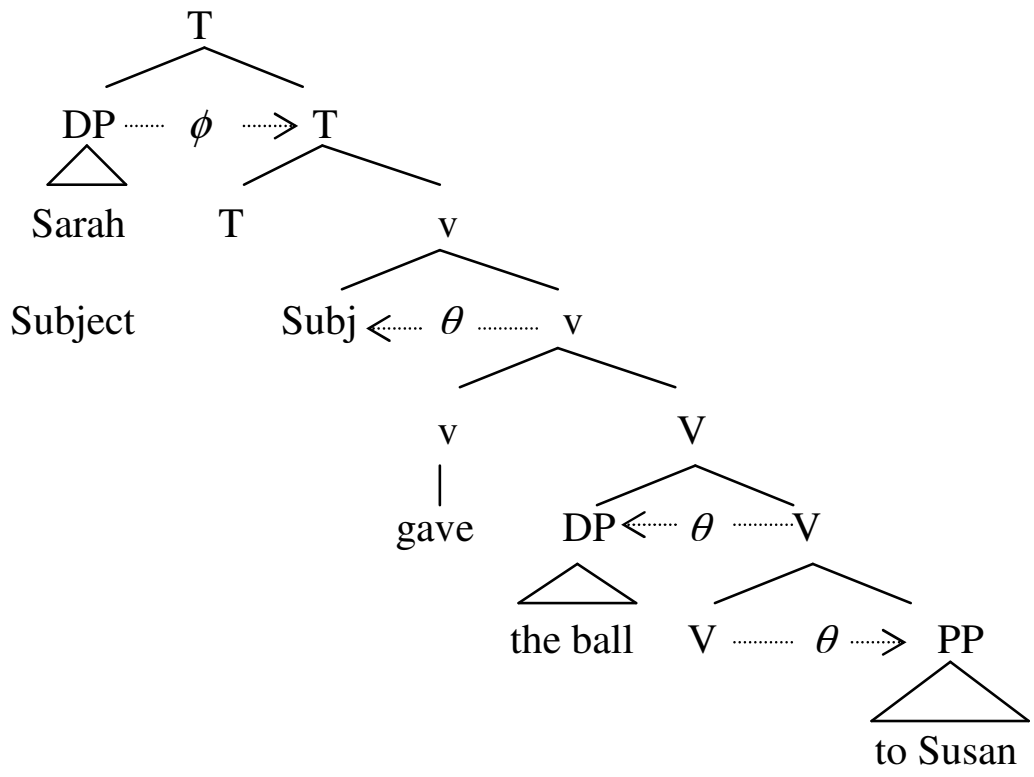

Consider the functional dependencies in the tree in (12), some of which are informally represented by arrows. Within the verb shell, since selection is an instantiation of functional dependency (10), $v$ functionally determines $\mathrm{V}$ as well as the DP in SpecvP. V and the light verb $(v)$ each select arguments and assign Theta-roles. Thus, each of the arguments is functionally determined by a verbal head. Within the verb shell, none of the arguments functionally determine any other element. Similarly, in the functional layer, $\mathrm{T}$ will functionally determine $v$ and, by the Transitivity rule in (9c), everything contained in $v$. This situation changes dramatically when one considers the status of the DP in SpecTP. T assigns Case to the subject DP and consequently functionally determines it. However, $\phi$ features (GOAL) in DP also determine the values of their corresponding uninterpretable features (PROBE) on T. Thus, the $\phi$ features of the subject DP functionally determine $\mathrm{T}$ and, by the Transitivity rule in $(9 \mathrm{c})$, everything contained within it. ${ }^{12}$ 
Thus, functional dependency exposes an asymmetry between subject DPs and other DP arguments. Subject DPs are functional determiners; non-subjects are functionally determined and do not functionally determine any other element in the representation. It is this asymmetry which I propose underpins the notion of SUBJECT. Any DP which functionally determines some feature can be regarded as a SUBJECT. Typically, such features will be formal features.

(13) a. SUBJECT: A DP which functionally determines a $\phi$ feature is a SUBJECT.

b. Binding domain: The minimal domain containing an anaphor, a potential binder, and a SUBJECT.

\subsection{Possessive DPs as subjects}

This paper began with the problem of defining SUBJECT as it pertains to binding domains. Having provided an elegant definition of SUBJECT and binding domain in (13), I will now demonstrate how this definition fares with respect to the data. Considering first examples such as that in (14), in situations where the SUBJECT is also the clausal subject, the data are easily explained. Since the clausal subject will always agree with $\mathrm{T}$, the clausal subject will always functionally determine $\phi$ features of $\mathrm{T}$ and will consequently always be a SUBJECT. Clausal subjects will thus always determine a domain for binding.

(14) $\|_{\text {Sub }}$ The twins ${ }_{i}$ expected that $\|_{\text {Sub }}[\mathrm{I}]$ would help $*$ each other ${ }_{i} /$ them $_{i}$

Above it was shown that possessors are SUBJECTs. In (15a), there is no possessor/subject and the reciprocal can be bound by the sentential subject they. In (15b), in contrast, a possessor/subject is present within the DP and induces a domain; the reciprocal cannot be bound by the sentential subject, as it now lies outside the binding domain. These examples show that the binding domain is defined by the presence of an overt SUBJECT.
a. $\|_{\text {Sub }}$ They $_{\mathrm{i}}$ read $\quad$ [ ] books about each other $\mathrm{r}_{\mathrm{i}} / *^{*}$ them $_{\mathrm{i}}$
b. $\|_{\text {Sub }}$ They $_{\mathrm{i}}$ read $\|_{\text {Sub }}$ [Mary's] books about $*$ each other ${ }_{i} /$ them $_{i}$

(Harbert 1995: 184-185)

These data are puzzling from a traditional perspective. First there is the problem of why a possessor DP should count as a subject at all, as this is not an intuitive idea (i.e. the possessive 
DP is optional, not necessarily agentive, does not determine agreement in English, etc.). Second, if one requires a subject position or field to determine a domain, then there is clearly a position available, whether or not it is filled. Thus, in contexts where there is no possessor $\mathrm{DP}$, it is not necessarily obvious that there should also be no binding domain. ${ }^{13}$

The definition of SUBJECT in terms of the functional dependencies in (13) immediately makes the prediction that, if possessors are binding domains, then the non-clausal possessive pronoun should functionally determine its complement in the same way that a clausal DP subject functionally determines agreement on $\mathrm{T}$.
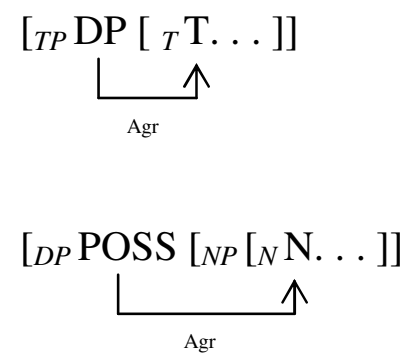

Although in English it is not immediately clear that the English possessive functionally determines its complement, there is a range of research which shows that DPs parallel the architecture of clauses (e.g. Szabolcsi 1983, 1994). But making the claim that SpecDP is analogous to SpecTP does not really provide any deep explanations; why should D and T be analogous, since at a feature level they appear quite different? ${ }^{14}$ What is it about the relationship between DP and $\mathrm{T}$ and $\mathrm{N}$, respectively, that makes the DP a subject?

The functional dependency proposal makes a clear prediction: the DP in SpecTP and SpecDP should functionally determine features on $\mathrm{T}$ and $\mathrm{N}$, respectively. The crucial evidence for functional dependency comes from Hungarian, where overt agreement occurs between a possessive and its complement. In (18), the subject marking - $m$ occurs in both clausal and possessive contexts.

$$
\begin{aligned}
& \text { a. (Én) alud-t-am } \\
& \text { I sleep-PAST-1SG } \\
& \text { "I slept" }
\end{aligned}
$$


b. azén vendég-e-m

the I guest-POSS-1SG

"my guest"

Hungarian (Liptak, p.c.)

The possessive pronoun determines agreement morphology on $\mathrm{N}$ in the same way that DP subjects determine agreement morphology on $\mathrm{T}$. This shows that SUBJECTs in both these contexts can be unified by the fact that both functionally determine their complements. This is a very important result; it confirms that the central characteristic underlying binding domains is functional dependency - in this case, expressed by means of agreement.

\section{Subject-oriented anaphors}

This section deals with another issue in binding that is not at all predicted by Standard Binding theory, namely subject-oriented anaphors. It will be argued that the central device underpinning this phenomenon is SUBJECT, defined in terms of functional dependency. The discussion is adapted from (De Vos 2006a,b).

The term "subject-oriented anaphor" (SOA) is a generic term that I will use to describe anaphoric phenomena that exclusively have a subject as an antecedent. A Dutch example of a local SOA is given in (19). The anaphor zich can only be bound by the clausal subject Jan.

a. $J_{a n}$ zag een slang naast zich

$\mathrm{Jan}_{i}$ saw a snake near $\mathrm{REFL}_{i}$

Dutch (Koster 1985: 145)

b. $\quad$ SUBJECT $_{i} \ldots$ OBJECT $_{i} \ldots \mathrm{REFL}_{i}$

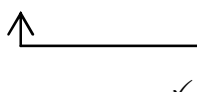

Many other languages have SOAs that are bound by long-distance antecedents. In fact, SOAs are often thought always to be long-distance anaphors, a notion contradicted by the Dutch data in (19). Although my analysis is applicable to SOAs generally, in the present discussion I will concentrate on long-distance anaphors more specifically. Typically, the domain for these 
long-distance SOAs is at least the minimal tensed clause, with additional antecedents at longer distance also being possible under some conditions (cf. Koster and Reuland 1991, and references therein). These SOAs do not seem to obey Principle A.

(20) a. $\quad \|_{S u b}$ Zhangsan $_{i}$ gaosu Lisi $i_{k} \quad \|_{S u b}$ Wangwu $_{j}$ xihuan ziji $i_{i j / * k}$

Zhangsan $_{\mathrm{i}}$ tell Lisi $_{\mathrm{k}} \quad$ Wangwu $_{\mathrm{j}}$ like REFL $_{\mathrm{i} / \mathrm{j} / *_{\mathrm{k}}}$

$\begin{array}{lll}\text { SUBJECT } & \text { OBJECT } & \text { SUBJECT }\end{array}$

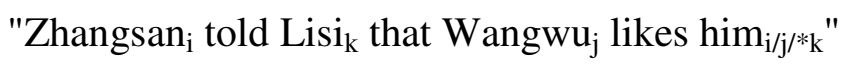

Mandarin (Huang, p.c.)

b.

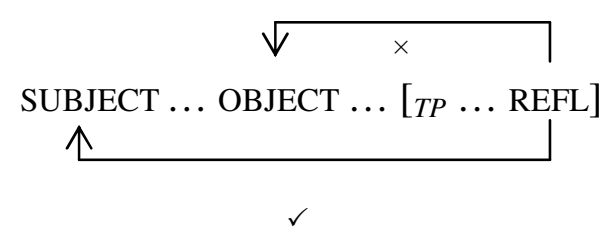

c. Pétur bað Jens $_{j}$ um PRO $\mathrm{PR}_{j}$ að raka $\operatorname{sig}_{i / * j}$

Pétur ${ }_{\mathrm{i}}$ asked Jens $\mathrm{j}_{\mathrm{j}}$ PREP PRO $_{\mathrm{j}}$ to shave $\mathrm{REFL}_{\mathrm{i} /{ } \mathrm{j}}$

"Peter asked Jens to shave him"

Icelandic (Harbert 1995: 192)

d. At Peter $_{i}$ bad Anne om $_{\text {or }}$ [PRO at ringe til sig $\left._{i}\right]$

that Peter ${ }_{i}$ asked Anne ${ }_{k}$ PREP to ring to $\mathrm{REFL}_{i}$

"that Peter asked Anne to ring him"

Danish (Thráinsson 1991: 51)

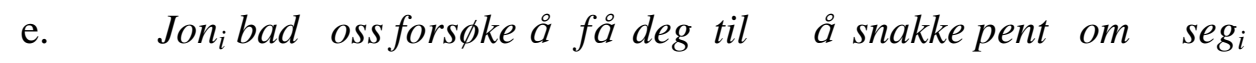

Jon $_{\mathrm{i}}$ asked us try to get you COMP to speak nicely about REFL $\mathrm{i}_{\mathrm{i}}$

"Jon asked us to try to get you to speak nicely about him"

Norwegian (Hellan 1991: 30)

The example in (20a) has two finite clauses with an antecedent, namely Wangwu in the minimal tensed clause. In addition, it is possible for the subject of the matrix clause, namely Zhangsan, to bind the anaphor, yielding an ambiguous reading for the anaphor. Importantly, 
both possible antecedents are subjects of their respective clauses; the non-subject, namely Lisi, cannot be an antecedent, contrary to what is predicted by Principle A. The configuration schematically represented in $(20 \mathrm{~b})$. The data are similar to SOAs in many other languages, including Icelandic, Norwegian and Danish. ${ }^{16}$

Long-distance anaphors (LDAs) have several characteristics in common (Pica 1986, 1991; Koster and Reuland 1991; Cole and Hermon 2005), as given in (21).

(21) a. Antecedents must be subjects (hence they are SOAs);

b. LDAs allow an antecedent outside the governing category;

c. LDAs are restricted to reflexives; reciprocals are never LDAs;

d. LDAs are monomorphemic; morphologically complex anaphors are local (Everaert 1991);

e. In languages without subject-verb agreement, LDAs exhibit the Blocking Effect; ${ }^{17}$ and

f. Outside the local domain there is no complementarity between pronouns and LDAs.

What these cross-linguistic correlations suggest is that SOAs are subject to strong crosslinguistic principles, and that there must be some syntactic operation which can distinguish subjects from non-subjects.

(22) a. Generalization 1: Structurally licensed LDAs are subject oriented.

b. Generalization 2: Some local anaphors are subject oriented.

c. Corollary: Some syntactic operation must exist which distinguishes between subjects and non-subjects.

Thus far in this paper, I have demonstrated that functional dependencies can make the above distinction, and I would like to propose that functional dependencies are responsible for the subject-oriented nature of SOAs. I will not, however, derive all the properties in (21); merely their subject-oriented nature. 


\subsection{SOAs are not logophors}

It might be claimed that SOAs are simply logophors. Logophors seem to be determined by discourse and prominence factors, rather than structural configurations. Thus, English "picture anaphors" do not always require a C-commanding antecedent, as in (23); Icelandic anaphors can have non-structural, pragmatic antecedents, as in (24); Korean anaphors can be determined by discourse topics, as in (25); and Malay anaphors can be bound by discourse prominent antecedents, as in (26).

(23) [That we hang a picture of himself $f_{i}$ on every wall] is one of the president's $s_{i}$ most outrageous demands

English (Reinhart and Reuland 1991: 317)

(24) María ${ }_{i}$ var alltaf svo andstyggilig. pegar Ólafur ${ }_{j}$ kaemi segði hún sér ${ }_{i{ }^{*} j}$ áreiðanlega aðfara Maria $\mathrm{i}_{\mathrm{i}}$ was always so nasty. When $\mathrm{Olaf}_{\mathrm{j}}$ came she said she $\mathrm{REFL}_{\mathrm{i} /{ }_{\mathrm{j}}}$ certainly had to leave Icelandic (Thráinsson 1991: 53)

(25) A: Mary $_{i}$-ka ku pati-e kass-ni anim tarum salam-i taysin kass-ni? Mary-NOM the party-to went-Q or other person-NOM instead go-Q "Is it Mary $\mathrm{i}_{\mathrm{i}}$ who went to the party or somebody else instead?"

B: Ani, cak $_{\mathrm{i}}$-ka kasse no $\mathrm{REFL}_{\mathrm{i}}$-NOM went

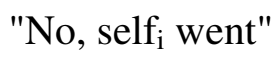

Korean (Gill 1999: 173)

(26) Siti mengingatkan Mohamed $_{j}$ yang saya tahu dirinya ${ }_{i / j / k}$

Siti $_{i}$ remind $\quad$ Mohamed $_{j}$ that $1 \mathrm{SG}$ know REFL. $3 \mathrm{sg}_{\mathrm{i} / \mathrm{j} / \mathrm{k}}$

"Siti reminded Mohamed that I know s/he is a criminal"

Malay (Cole and Hermon 2005: 629)

In all the examples in (23) to (26), the logophoric element is licensed by antecedents which are not necessarily represented in the syntactic structure, and are not necessarily subjects. 
There are several reasons to claim that SOAs are distinct from logophoric phenomena. First, example (19) is an SOA that is obligatorily local. With the exception of its local character, it conforms with the properties in (21). Since logophors are characteristically non-local, SOAs cannot all be logophors. Another reason to exclude logophors from this category is that logophors can operate at arbitrary distances from the antecedent, may not necessarily have an antecedent at all, and need not be in a C-command relationship with the antecedent. In contrast, SOAs must be bound by a C-commanding antecedent, an antecedent is obligatory, and the antecedent must be within a domain typically defined by the tensed clause (Koster and Reuland 1991) (again, abstracting away from the local character of Dutch zich). Koster and Reuland (1991) suggest that there are three domains for binding, namely (i) the local domain for himself type anaphors, (ii) a medium-range domain for SOAs, and (iii) a larger domain for logophors. All these properties suggest that SOAs are distinct from logophors. Finally, SOAs are cross-linguistically morphologically simplex (as opposed to local anaphors like himself). There is no such restriction on logophors, which can be complex.

For these reasons, I argue against lumping SOAs together with logophors. Doing so would obscure strong cross-linguistic correlations. Consequently, I will continue to treat SOAs as a distinct set of anaphoric possibilities. By excluding logophors, it is also possible to make the claim that the strong subject-oriented character of SOAs must be derived from some deeper principle of grammar.

\subsection{Previous analyses of SOAs}

It has been proposed that constructions with SOAs are derived by head movement (Pica 1986; Cole, Hermon, and Sung 1990; Huang and Tang 1991). SOAs are always monomorphemic and are thus consistent with head status. It has been proposed that such a head can adjoin to the subject.

a. Zhangsan gaosu Lisi $_{k}$ Wangwu ${\text { Xihuan } z i j i_{i j / * k}}$

Zhangsan $_{\mathrm{i}}$ tell Lisi $_{\mathrm{k}}$ Wangwu $_{\mathrm{j}}$ like REFL $_{\mathrm{i} / \mathrm{j} / \mathrm{k}_{\mathrm{k}}}$

SUBJECT OBJECT SUBJECT REFL

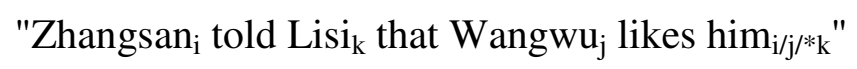




\section{b. Zhangsan ${ }_{i}\left[z i j i_{i j j}\right]$ gaosu Lisi $i_{k} \quad$ Wangwu $_{j}\left[z i j i_{j}\right]$ xihuan $z i j i_{i j / * * k}$ Zhangsan $_{\mathrm{i}} \mathrm{REFL}_{\mathrm{i} / \mathrm{j}}$ tell Lisi $_{\mathrm{k}}$ Wangwu $_{\mathrm{j}} \mathrm{REFL}_{\mathrm{j}}$ like $\mathrm{REFL}_{\mathrm{i} / \mathrm{j} / * \mathrm{k}}$ \\ $\uparrow$ 个}

By assumption, the reflexive head can only be bound when it moves into a local adjunction relation with its antecedent. Thus, reflexive binding is contingent on head movement. This approach requires that head-movement can occur between clauses. ${ }^{18}$ In example (27), the reflexive head, ziji adjoins to INFL and is bound by the subject located in SpecIP. Nothing prevents the reflexive from undergoing cyclic head movement, thus allowing it to be bound by every subject in the sentence. Importantly, however, since the anaphor is already bound by Wangwu, the higher antecedent must match the features of the lower antecedent, in this case, 3SG.

However, this analysis cannot be correct for all SOAs, especially those found in the Germanic languages. The central criticism of the approach stems from generalization (21e). In languages with no agreement (e.g. Mandarin Chinese), SOAs are subject to a "blocking" effect. Long distance antecedents are only possible if the long-distance antecedent agrees with the possible antecedents beneath it. This has been used as a diagnostic for a head-movement analysis of these anaphors (Pica 1986; Huang and Tang 1991; Huang 1996; ; Cole et al. 1993; Cole and Hermon 2005).

(28) $\mathrm{Ni}_{i} \quad$ renwei wo $_{j} \quad$ zhidao ziji $*_{* i j}$ de taitai shi yige da hao ren you $_{\mathrm{i}}$.2SG think $\mathrm{I}_{\mathrm{j}}$. $1 \mathrm{SG}$ know REFL $*_{i j}$ POSS wife is one big good man "You think that I knew that my own wife was a very good person"

(Cole and Hermon 2005: 628)

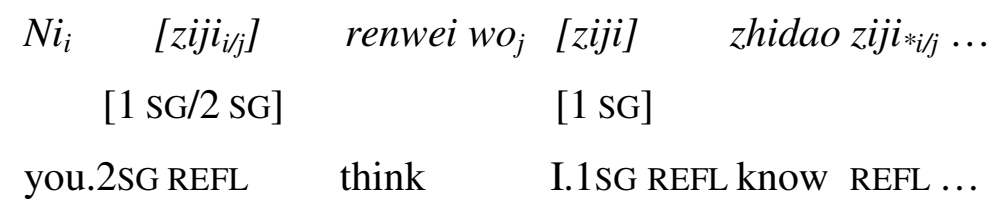

The local subject wo differs in features from the long-distance subject $n i$. The reflexive head $z i j i$ adjoins to INFL of the embedded clause, where it agrees with the features of the subject: 1SG. If it were to undergo further movement to adjoin to INFL of the matrix clause, then it would also have to agree with the matrix subject: $2 \mathrm{SG}$. This would result in a clash of features. 
Thus, the SOA can only be bound by the local subject, because the two subjects do not agree. This is known as the "blocking" effect, and has been used as an indicator that the SOA ziji must adjoin to the local subject before it can be bound by the long-distance subject. This analysis is not available for the Germanic languages, as the blocking effect is not visible.

Jón segir að pú elskir sigi/hann $_{i}$

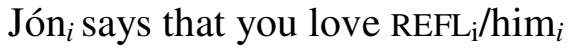

"Jón ${ }_{i}$ says that you love $\operatorname{him}_{i} "$

Icelandic (Sigurðsson 1990: 309)

In example (30), the subjects of the embedded and matrix clauses differ in terms of their features. Yet the fact that the matrix subject can be an antecedent of the reflexive shows that there is no blocking effect. Consequently, this example cannot be derived by the headmovement analysis.

Another argument against the universal validity of the head-movement analysis is that SOAs can occur in islands in Icelandic (Thráinsson 1991: 57). The examples in (31) show that an anaphor can occur in a context where WH extraction is not possible. This militates against an analysis that involves movement of the anaphor. These arguments show that not all SOAs reduce to head-movement.

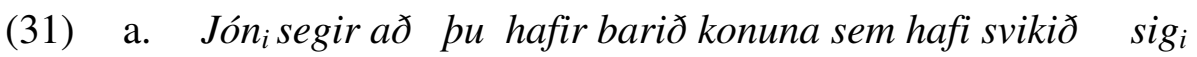
Jón $_{i}$ says that you have hit woman that has betrayed $\mathrm{REFL}_{i}$ "Jón says that you hit the woman that betrayed him"

b. *Hvern segir Jón að pu hafir barið konuna sem hafi svikið? who says Jón that you have hit woman that has betrayed "Who does Jón say that you have hit the woman that has betrayed $t$ ?"

Icelandic (Thráinsson 1991: 57)

\subsection{Proposal: SOAs are sensitive to functional dependency}

That subjects should be important in defining some kinds of antecedents is not surprising, given the prominent role played by subjects in defining binding domains more generally: the 
binding domain of local anaphors is delimited by the closest accessible SUBJECT (see above). The real question is how to express this intuition in formal terms: from what fundamental principles does subjecthood derive? As should by now be clear, I will argue that SUBJECT defined in terms of functional dependencies is responsible.

Traditionally, anaphors are bound by a command relation, namely C-command. ${ }^{19}$ Although it is usually assumed that $\mathrm{C}$-command is the sole command relation available to narrow syntax, if the results of the analyses above are correct, then there must be another command relation based on functional dependencies. Recall that functional dependencies follow from standard assumptions about phrase structure and syntactic relationships. These assumptions lead to the conclusion that functional dependencies are inherent in syntactic representations. Thus, it would be very surprising if narrow syntax did not make use of them. I therefore propose that there is a typological distinction between those anaphors that are bound by C-command and those that are bound by SUBJECT defined in terms of functional dependency.

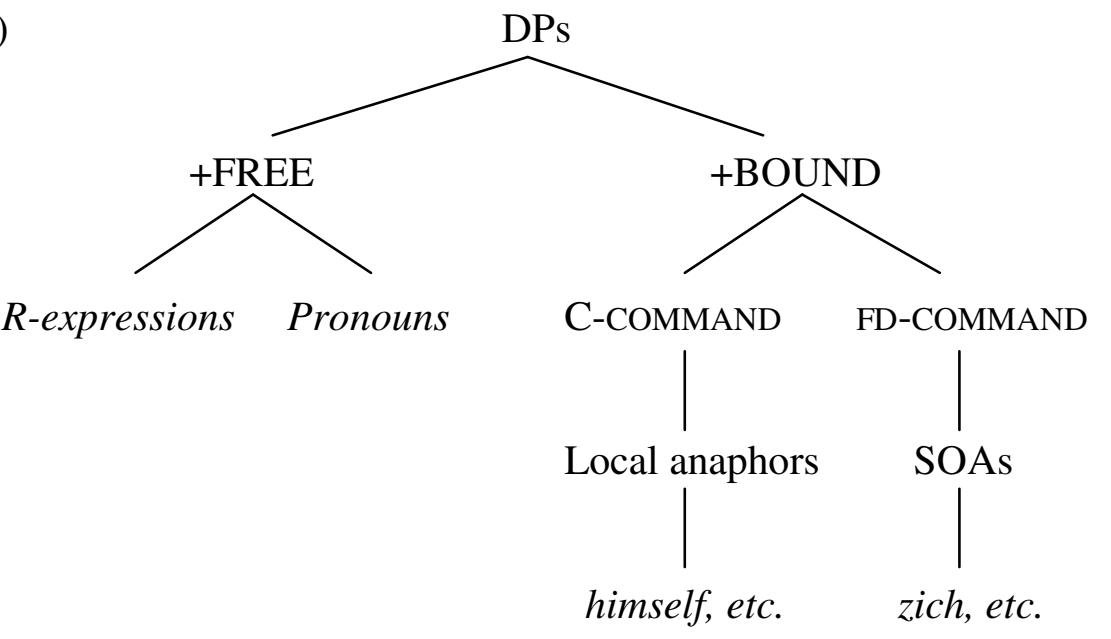

Note that C-command and functional dependency-command are distinct types of command relationship. ${ }^{20}$ Importantly, however, the notion of SUBJECT is central. If one assumes the existence of SUBJECT for the purposes of the standard Binding Theory, then one must also accept it for the purposes of SOAs. The purpose of the present paper has been to provide a formal account of what a SUBJECT is.

SOAs sensitive to functional dependency will only be bound by the subject, and never by a non-subject. They may or may not be local - modulo minimality constraints on intervening 
antecedents. ${ }^{21}$ C-command anaphors, however, will always be bound by a C-commanding antecedent. $^{22}$ This leads me to tentatively redefine the domain condition of Principle A of the Binding Theory in terms of functional dependency, as in (33).

(33) Principle A: An anaphoric, NP must be:
A1: C-command bound in a binding domain $\delta$
[Local himself-type] OR

A2: Functional dependency bound in a binding domain $\delta \quad$ [SOA zich-type]

Domain: (Tentative) The domain $\delta$ is the first DP which functionally determines the reflexive (see (13))

\subsubsection{Relativizing the notion 'domain'}

The main question that is raised by (33) is how to parameterize anaphors in such a way that the binding domain $\delta$ is slightly different for SOAs and himself-type anaphors. Although this question would require a much longer paper, one which would effectively redefine the Binding Theory, some speculations are in order here.

Note that self-type anaphors are sensitive to the number of the antecedent - there are morphological reflexes of number, as in himself, themselves, etc. Zich-type anaphors do not have a morphological reflex for number. Conversely, zich-type anaphors are sensitive to person; a first or second-person antecedent cannot bind a zich-type anaphor. The same is not true of self-type anaphors, as in myself, yourself, etc. ${ }^{23}$ Drawing on these facts, and on the earlier assumption that anaphors are defective in terms of some $\phi$ features, I tentatively propose that the domains of these anaphors be defined as in (34).

(34) The domain of an anaphoric, self-type NP

SELF-Domain: (Tentative) The domain $\delta$ is the first DP which functionally determines the reflexive in terms of NUMBER features.

This accounts for English-type anaphors, as the domain defined by a subject which agrees in terms of number will always be TP, even in PRO clauses. ${ }^{24}$ 
(35) The domain of an anaphoric, zich-type NP

ZICH-Domain: (Tentative) The domain $\delta$ is the first DP which functionally determines the reflexive in terms of PERSON features.

This accounts for typical SOA examples, such as that from Icelandic in (36).

Pétur $_{i}$ bað Jens um PRO að raka sig

Petur $_{i}$ asked Jens PREP PRO to shave REFL

Icelandic (Harbert 1995: 192)

If the reflexive is lexically specified as being functional dependency-bound, then the matrix subject Petur is a possible antecedent. The grammatical object Jens cannot be a possible antecedent. $^{25}$ The domain of the SOA is also defined by the matrix subject, which agrees in terms of person and number.

\subsubsection{PRO and $N$ agreement in infinitives}

At this point, a question is raised by the existence of a PRO subject in (36). After all, PRO seems to be a SUBJECT, so it should also bind the SOA, contrary to fact. PRO "subjects" of infinitives are potentially a little more complicated than subjects of finite clauses, as there is considerable variation in the typology of infinitive clauses with respect to temporal reference, etc.

The prediction made in section 6.3.1 is that, since PRO does not define a domain for longdistance SOAs, PRO cannot agree with $\mathrm{T}$ in terms of person features. It has been argued that two types of infinitives exist, based on independent time reference or lack thereof (Stowell 1982). In addition, some languages have overt inflection in infinitives (e.g. Portuguese). A full discussion of the nature of agreement in infinitives is beyond the scope of this paper. Nevertheless, some preliminary observations are in order.

The example in (36) has an event in the embedded clause which is temporally unordered with respect to the moment of utterance (speech time) (Stowell 1982; Wurmbrand 2001; Cowper 2005). 
(37) a. Pétur asked Jens (yesterday) to shave him (yesterday/sometime later today)

b. $[S, R]^{26}$

Cowper (2005: 26-27) claims that these kinds of infinitives lack a temporal deixis feature specifying the relationship of Speech Time and Reference Time. Within Cowper's featuregeometric approach, this entails that such infinitival clauses also cannot have a person deixis specification, as without temporal deixis, person deixis cannot be interpreted (Cowper 2005: $18,27)$.

If this is the case, then in (36), the infinitival clause may lack a fully-fledged INFL/Agreement projection, and consequently, PRO would not determine PERSON agreement on T and could neither functionally determine the anaphor nor define a domain for the anaphor. This would preclude PRO from being a suitable antecedent in this particular context. Thus, the prediction appears to be confirmed although it is likely that infinitival clauses differ from language to language in this respect. These intriguing issues await future research.

\section{Evidence for functional dependencies}

In addition to the conceptual argument for functional dependencies, the treatment of functional dependencies in binding domains, and the discussion about SOAs, I provide here some additional arguments in favour of the analysis proposed above.

\subsection{Object agreement}

A prediction of the functional dependency approach is that, if the agreement between a DP and $\mathrm{T}$ constitutes a SUBJECT, and ultimately licenses SOAs, then languages with object agreement should allow the object to bind SOAs. The reason for this is that the agreeing object will act as an intervener between an agreeing subject and an SOA - in effect, the agreeing object will act as a kind of SUBJECT.

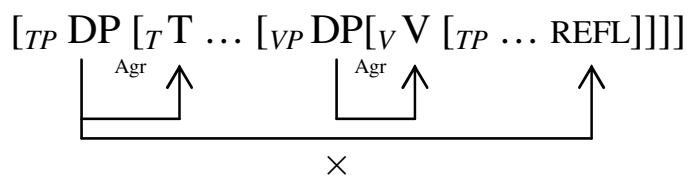


First, note that the functional dependency approach does not make predictions about the availability of discourse logophors. As I have done throughout this paper, I will focus exclusively on SOAs (but cf. section 7.3.2 for a brief discussion).

An initial survey provides circumstantial evidence in favour of this prediction. Languages with object-agreement do not have exclusive SOAs. However, this argument is incomplete because many object-agreement languages, such as Mohawk, do not have anaphoric NPs at all (Baker 1996, 2003), and consequently cannot shed light on the distribution of SOAs. Similarly, many Bantu languages have reciprocal markers on the verb itself, which affect the way binding operates in those languages. Nevertheless, there do exist languages such as Georgian, Hungarian, and Basque, which do have object agreement and which also have anaphoric NPs (Everaert 2001; Amiridze 2006; Liptak p.c.; Everaert p.c.; Rebuschi p.c.). Of these, presented in Table 1, none have SOAs. ${ }^{27}$

\begin{tabular}{|c|c|c|c|c|}
\hline Language & S-V Agree & V-O Agree & Non-Logophoric SOA & $\begin{array}{c}\text { Discourse } \\
\text { Logophors }\end{array}$ \\
\hline Icelandic & Yes & & Yes sig & sig \\
Norwegian & Yes & & Yes seg & \\
Dutch & Yes & & Yes zich & \\
Finnish & Yes & Yes itse & \\
\hline Basque & Yes & Yes & No & \\
Georgian & Yes & Yes & No & \\
Hungarian & Yes & Yes & No & Himself (Kennedy \\
and Lidz 2001) \\
English & No(?) & & & Dirinja (Cole and \\
& & & No & Hermon 2005) \\
Afrikaans & No & & No & Caki (Gells 1987) \\
Malay & No & & & \\
& & & No & \\
Japanese & No & & No & \\
Korean & No & & Yes ziji & \\
Mandarin Chinese & No & & & \\
\hline
\end{tabular}

Table 1. Classification of languages in terms of object agreement, anaphoric NPs, and SOAs

\subsection{Italian agreement and binding}

More direct evidence for this position comes from Italian. ${ }^{28}$ Italian is a useful illustrative example here, as it does not have object agreement, and thus licenses SOAs like proprio. This lexeme is an SOA when it acts as an LDA (Giorgi 1991: 186); when it is bound locally within its clause, then it can be bound either by the subject or the object. This dual character of proprio makes it ideal for exploring the interaction of agreement and binding. In fact, it can 
be shown that the antecedent of proprio is, in part, determined by agreement - and thus by functional dependency.

Example (39a) shows an object with a PP complement containing a reflexive. Only the grammatical subject is an appropriate antecedent for the reflexive. The preposition is underlined for ease of reference. In contrast, an adjectival complement (39b, underlined) does allow the object as a suitable antecedent for the reflexive.

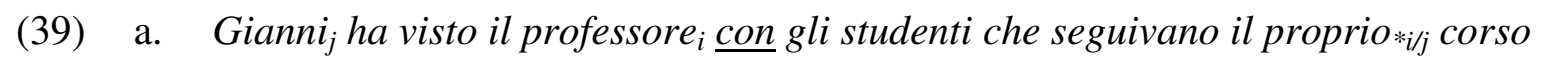
Gianni $_{j}$ saw the professor ${ }_{i}$ with the students who followed REFL $*_{i j}$ class "Gianni saw the professor with the students who attended his class"

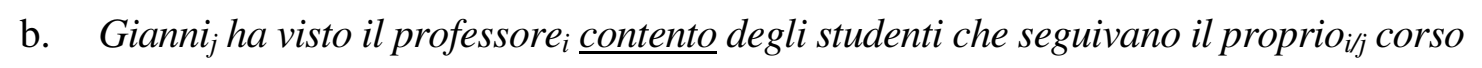
Gianni $_{j} \quad$ saw the professor $_{i}$ satisfied with the students who followed REFL $i / j$ class Intended: "Gianni saw the professor to be satisfied with the students who followed his class"

(Giorgi 1991: 188)

The data is supported by evidence that DP complements in (40) pattern with adjectives and not PPs. The general structure of these examples is illustrated in (41). Although the structures are identical, only for AP and NP complements does the NP small clause subject functionally determine the complement, as evidenced by overt agreement. The dotted line informally illustrates the functional dependency.

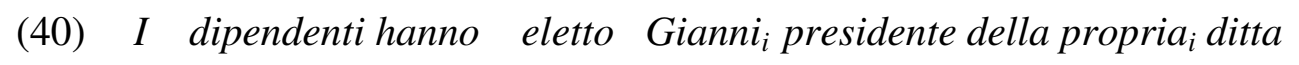
the dependent workers elected Gianni $i_{i}$ president of $\mathrm{REFL}_{\mathrm{i}}$ firm "The workers elected Gianni president of his firm"

(Giorgi 1991: 189) 
$(41)$

a.

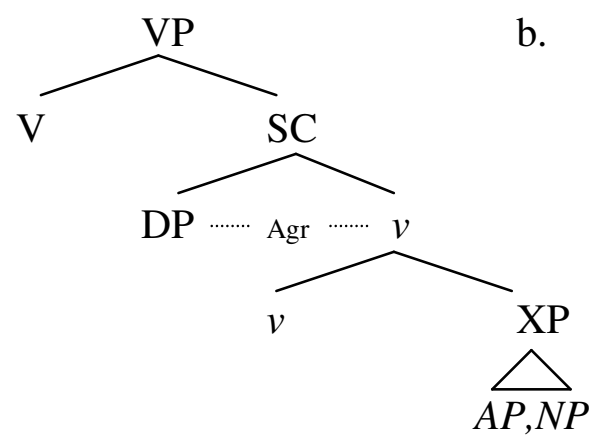

b.

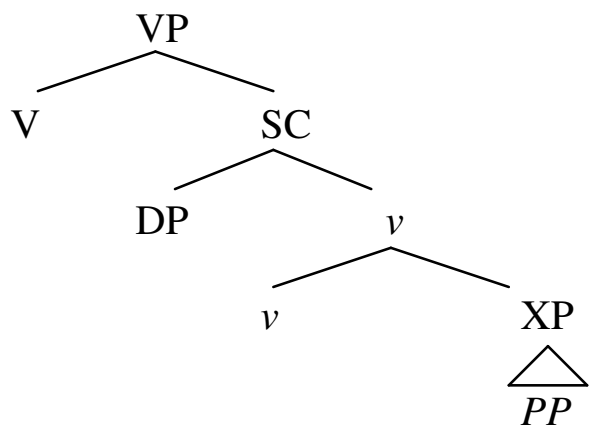

The broad generalization with these data is that, in contexts where the XP complement agrees with the small clause SUBJECT (i.e. APs and DPs but not PPs), a reflexive is licensed. In other words, for SCs with PPs, the DP is not a true SUBJECT at all, because it does not functionally determine PP. This is strong evidence for a functional dependency approach.

As suggested by an anonymous reviewer, in a tree such as (41b), the DP could functionally determine an XP if the DP functionally determined some entity (such as a reflexive) inside the XP itself.

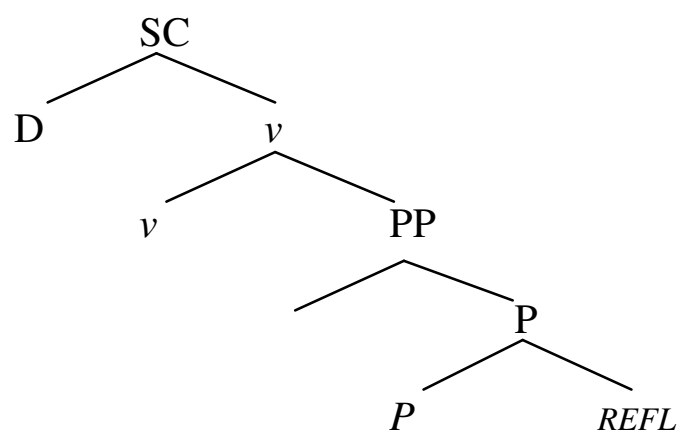

The implication is that the presence of a reflexive inside a PP could open up the PP, allowing it to be functionally determined. In other words, one might expect the presence of agreement to be contingent on the presence of a reflexive within that phrase - contrary to fact.

The functional dependency approach does not make this kind of prediction. Although the difference is subtle, from a functional dependency perspective, such a view is from the wrong direction. If a DP functionally determines the PP, then it will also functionally determine everything inside the PP. Thus, if agreement is present (being indicative of an underlying functional dependency), then it will be possible to bind the reflexive. Thus, reflexive binding 
is contingent on functional dependency, and not vice versa. ${ }^{29}$ The data in (41) also militate against a solution in terms of C-command. In both (41a) and (41b), the DP C-commands the reflexive. Yet, only in (41a) does the DP functionally determine the reflexive. ${ }^{30}$

\subsection{Icelandic anaphors}

This section examines putative counter evidence to the main proposal of this paper. It will be shown that the proposal makes a prediction about the nature of Icelandic quirky subjects which turns out to be true. The Icelandic data will thus ultimately support the analysis.

The proposal thus far is as follows: an SOA is bound by a SUBJECT defined by functional dependency, as in (13). If a DP functionally determines its sister, and if the sister (directly or indirectly) dominates the SOA, then the DP can be an antecedent for an SOA. The presence of the functional dependency is often indicated by agreement, where the DP determines some feature on its sister. Thus, in (43), where X functionally determines YP and YP dominates the reflexive (indirectly by transitivity), $\mathrm{X}$ can be an antecedent for the reflexive.

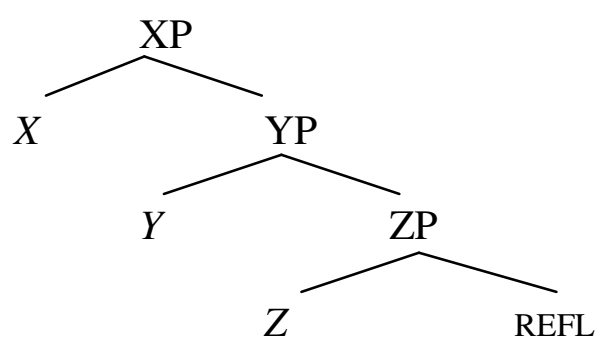

As far as the counter-evidence goes, note first that Icelandic has SOAs (Maling 1984), as in (44). In such examples, the reflexive possessive sinni can only be bound by the subject.

(44) Sigga $_{i} \quad$ barðimig meðdúkkunni sinni ${ }_{i}{ }^{*}$ hennar $_{i}$

Sigga $_{\mathrm{i}}$.NOM hit me.ACC with doll.DAT REFL $_{\mathrm{i}} / \mathrm{her}_{\mathrm{i}}$.POSS

"Sigga hit me with her doll"

(Zaenen et al. 1985: 101)

In Icelandic quirky case constructions, various tests indicate that the quirky DP is a clausal subject (Maling 1984; Zaenen et al. 1985). In particular, the dative DP can bind an SOA, as in (45). The nominative DP cannot bind an SOA. 
Henni $_{i}$ voru (ekkistrax) sagðar/gefnar uplýsingarnar um að she-DAT $T_{\mathrm{i}}$ were.PL (not immediately) told.PL/given.PL the.news.PL about that madurinn $\sin _{i}$ vri dáinn husband REFL $_{i}$ was dead "She was not immediately told/given the news that her husband was dead"

(Maling, p.c)

(46) Henni líkuðu ekki upplýsingarnar um að maðurinn sinn/hennar vri dáinn she-DAT $\mathrm{i}_{\mathrm{i}}$ liked-PL. not news.the.PL about COMP husband REFL $\mathrm{H}_{\mathrm{i}} / \mathrm{her}_{\mathrm{i}}$ was dead "She did not like the news that her husband was dead"

(Maling, p.c)

In example (45), the subject henni is marked with dative case. It is this quirky subject which is the antecedent of the SOA sin. The nominative DP uplysingarnar cannot bind the anaphor. The verb has plural agreement with the nominative DP. This constitutes counter-evidence to the proposal. This means that the Icelandic data are an important test-case for the current proposal.

\subsubsection{Icelandic dative agreement}

This is potentially problematic for the approach to SOAs proposed in this paper. I have claimed that SOAs are sensitive to functional dependencies. The data in (45) clearly show that it is the nominative DP which determines agreement on the verb, and yet the quirky dativecase-marked DP is the antecedent of the SOA. If the current proposal is to be sustained, there must be agreement between the quirky DP and the verb. Note that agreement need only be with a single feature in order to constitute a functional dependency (see the above definition of functional dependency). In particular, the prediction of section 6.3.1 is that the dative-casemarked DP must agree with the verb in terms of person features. Two interrelated predictions emerge, as given in (47) and (48). If the second is correct, there is evidence for relativized domains and functional dependencies. If only the first is correct, there is evidence for functional dependencies, but the approach to relativized domains will have to be reconsidered. 
(47) Prediction 1: Icelandic quirky dative-case-marked DPs must functionally determine the verb if they are to serve as antecedents for SOAs.

(48) Prediction 2: If the relativized approach to domains is correct (cf. section 6.3.1), then Icelandic quirky dative-case-marked DPs must functionally determine the verb in terms of person features if they are to serve as antecedents for SOAs.

A closer look at the Icelandic data confirms both predictions. First it should be noted that agreement between the verb and the nominative "object" does not display the clear-cut paradigm associated with prototypical subject-verb agreement (Taraldsen 1995; Sigurðsson 1996; Boeckx 2000b); "the facts get murky" (Boeckx 2000b: 357).

\section{a. Henni leiddust/*?leiddist Peir}

her.DAT.3SG bored.3PL/3SG they.NOM.3PL

"She was bored with them"

(Taraldsen 1995: 307)

b. Henni *leiddumst/?*leiddust/?leiddust/?*leiddist við

her.DAT bored.1PL/3PL/default we.1PL.NOM

"She was bored with us"

(Boeckx 2000b: 360)

Example (49a) shows that a 3PL nominative object triggers full agreement on the verb. However, (49b) shows that, when the nominative object is 1PL, then agreement fails. In fact, the sentence is ineffable. This contrasts with the clear-cut and consistent instances of agreement between a nominative subject and the verb in canonical finite clauses. The data suggest that agreement with the nominative object is in terms of number features. But agreement in terms of person is subject to additional constraints.

The problem is further illustrated with raising contexts. When there is more than one dative DP in the clause, then agreement with the nominative DP is not as clear cut. It appears that the dative DP of the embedded clause can determine agreement on the matrix raising verb to some extent. Thus, quirky dative subjects are not inert for agreement. The arrow informally represents agreement. 
(50) Mér fannst/*fundust henni leiðast Peir me.DAT seemed.3SG/3PL her.DAT bore they.NOM

"I thought she was bored by them"

(Boeckx 2000b: 359)

(51) Mér hefur/*hafa alltaf virst honum lika bakur me.DAT has.SG/have.PL often seemed him.DAT like books.NOM.PL

"It has often seemed to me that he likes books"

(Boeckx 2000b: 359)

Boeckx (2000b) argues that the presence of a quirky dative-case-marked subject blocks person agreement between the nominative DP and the raising verb. If the quirky DP induces minimality effects, then it must be the case that quirky DPs agree with verbs in person features. If the quirky DP had inert person features, then no minimality effect would be apparent. The following schema applies.

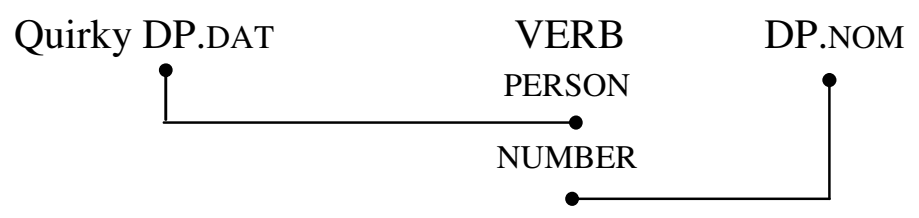

However, there is still the question of why person agreement is not morphologically realized. Boeckx (2000b) derives this from a universal typological constraint first proposed by Bonet (1994), given in (53).

... if person/number agreement on the verb obtains with a dative element (in the case of Icelandic, a quirky subject element), then verb agreement with the accusative DP must be third person (adapted from Boeckx 2000b: 365).

Although there is no actual morphological spell-out of this agreement, it is proposed by Boeckx (2000b) that the agreement between the dative subject and the verb cannot be morphologically realized because of the complex relationship between $\mathrm{T}$ and nominative case 
checking. By contrast, when the nominative object is first or second person, then the resulting sentences are predicted to be completely ungrammatical. This is borne out by the facts. In $(54 \mathrm{a}, \mathrm{b}, \mathrm{c})$, the examples are all ungrammatical because the nominative object is not 3rd person. This blocks person agreement between the dative subject and the verb.

$$
\begin{aligned}
& \text { a. Henni *leiddumst/?*leiddust/?*leiddist við } \\
& \text { her.DAT bored.1PL/3PL/default } \\
& \text { "She was bored with us" } \\
& \text { b. (Sigurðss } \\
& \text { benni voruð sýndir/sýndar ið } \\
& \text { her.DAT were shown.MASC/FEM you.NOM } \\
& \text { "You were shown to her" }
\end{aligned}
$$

(Sigurðsson 1996 in Boeckx 2000b: 360)

(Sigurðsson 1996 in Boeckx 2000b: 367)

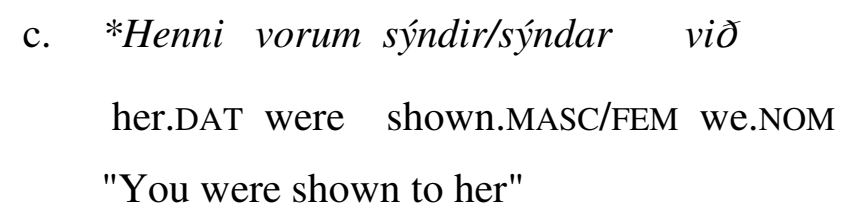

(Sigurðsson 1996 in Boeckx 2000b: 367)

Boeckx's (2000b) analysis demonstrates that the quirky DP functionally determines person features on the verb. This is sufficient to construe the quirky DP as a SUBJECT in terms of the definition in (13). Consequently, it is predicted that the quirky DP can function as an antecedent for SOAs, as demonstrated by (45). Thus, although the Icelandic data initially seemed problematic for the proposal, they ultimately follow from it.

\subsubsection{Features responsible for SOA binding}

If the results of the analyses above are correct, then an antecedent of an SOA must be a DP which functionally determines the anaphor with regard to (at least) person features. Some researchers (e.g. Hellan 1991) have posited the notion of 'perspective command' to account for the distributions of SOAs and logophors. For instance, Sigurðsson (1990) shows that Icelandic SOAs invoke "reference to a secondary ego from this ego's point of view" 
(Sigurðsson 1990: 328). This makes intuitive sense if one considers the PERSON specification as a speaker perspective (Boeckx 2000b; Levinson 2000). First person identifies the speaker, $I$; second person identifies the animate hearer; third person is for the rest. First person must always be a self-conscious agent capable of locution (i.e. +ANIMATE). Second person is less agentive, being consistent with passive listeners, but nevertheless must always be an entity capable of comprehension (i.e. +ANIMATE). ${ }^{31}$

Using person features makes an additional prediction: the antecedents of SOAs should be obligatorily animate - at least in Icelandic, given the analysis in section 7.3.1. It is worth pointing out that this restriction would remain puzzling under traditional Binding Theory.

This prediction is confirmed by Maling (p.c.): a local reflexive (i.e. a not exclusively subjectoriented reflexive) in Icelandic may have an inanimate antecedent, as in (55), but a longdistance reflexive must have an animate antecedent. ${ }^{32}$

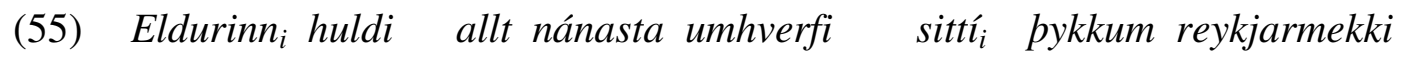 fire $_{\mathrm{i}}$-NOM covered all nearest surroundings $\mathrm{REFL}_{\mathrm{i}}$ thick smoke "Fire covered/veiled all the surroundings in its thick smoke"}

(Maling, p.c)

\section{Agreement vs. functional dependencies}

Throughout this paper, I have argued that functional dependencies underpin the notion of subjecthood. However, the evidence adduced in this paper could also be perceived as demonstrating that agreement is the foundation of subjecthood. The question could then arise as to whether we need bother with functional dependency at all.

Let us distinguish agreement from AGREE. Agreement is not a sufficient characterization of SUBJECTs for the following reasons. Not all languages have overt agreement. This is not to say that they do not have underlying functional dependencies - merely that in these languages, agreement is not an overt manifestation of such a functional dependency. Taking agreement alone as the necessary characteristic of subjecthood would amount to saying that these languages have no subjects. Importantly, a language like Mandarin Chinese exists, which has 
subject-oriented anaphora without having overt agreement. Similarly, Icelandic quirky-case constructions have subjects which can be characterized by functional dependencies, even though overt agreement does not take place.

The next reason why agreement alone cannot replace functional dependencies is that, as explained in section 1.1, agreement is only one particular empirical way of characterizing subjects in some languages; other defining features that have been proposed are correlations with nominative case, EPP, filler of SpecTP, etc. However, there are exceptions to all of these - including agreement.

What is needed is a theoretical means of distinguishing which of these criteria are central to subjecthood and which are, in effect, epiphenomenal. This paper has argued that functional dependencies are theoretically primitive, deriving from bare phrase structure (Chomsky $1995 b$ ), and that verbal $\phi$ agreement is one sufficient (but not necessary) overt reflex of an underlying functional dependency. ${ }^{33}$ Thus, functional dependencies provide a theoretical way of choosing between all the alternative ways of identifying subjects that have been proposed in the literature.

For instance, it has long been known that agreement determines binding domains. For instance, Leland and Kornfilt (1981) explored a Turkish dialect with agreeing and nonagreeing infinitives. Non-agreeing infinitives could not bind anaphors in their complement; agreeing ones could. This insight was incorporated into the Binding Theory of Chomsky (1981) by stipulation. There has not hitherto been any reason why this should be the case; the present paper provides the theoretical framework to formalize this insight.

Another area where functional dependency is useful, where simple agreement is less so, is in the domain of English expletive constructions. These may call into question the notion of subjects occupying SpecTP, because a non-agreeing expletive occupies SpecTP while the agreeing "associate" DP occupies SpecvP.

(56) There are three men on the roof 
While a considerable amount of ink has been spilled in accounting for these constructions, the functional dependency approach would simply claim that the true subject of the sentence is the associate DP, as this demonstrably functionally determines agreement. This does not, however, preclude a feature-movement approach, where the formal features of the associate raise to SpecTP. In short, the functional dependency approach is consistent with a variety of treatments within the Chomskyan paradigm. What the functional dependency approach does rule out is a situation where the expletive there is considered simultaneously the true subject of the sentence and also a pronoun: an independent pronoun could only be the true subject if it also agrees with the verb. ${ }^{34}$

Turning to the theoretical notion of AGREE, there are also reasons why AGREE alone cannot be the defining feature of subjecthood. ${ }^{35}$ It is important to realize that any instance of AGREE (where an interpretable feature determines the value of a corresponding uninterpretable feature) is also a functional dependency. The inverse does not necessarily hold, however. Crucial in this respect is the fact that AGREE is not transitive. If a DP agrees with T, then it is not valid to state that the DP also AGREEs with everything in the C-command domain of T. However, functional dependencies are, by definition, transitive, and if the DP functionally determines $\mathrm{T}$, then it also functionally determines everything in the domain of $\mathrm{T}$. This is important when dealing with SOAs, where the subject-antecedent functionally determines the SOA, even though the subject may not actually AGREE with the anaphor itself. It is the local agreement between the SUBJECT and its sister which allows the SOA to be transitively functionally determined. ${ }^{36}$

This opens the way for functional dependencies to circumvent certain kinds of minimality restrictions in a principled manner - an empirically necessary (if theoretically unwelcome) requirement in order to account for LDAs. In (57), the subject agrees with T, and thereby functionally determines the LDA. The object does not agree with anything, and thereby does not functionally determine the LDA. There is no minimality violation with respect to functional dependency, because there is no other DP closer to the anaphor which functionally determines it. This is not possible using AGREE: any AGREE relation between the subject and the anaphor will incur a minimality violation because of the existence of a closer DP with the same features as the subject. 


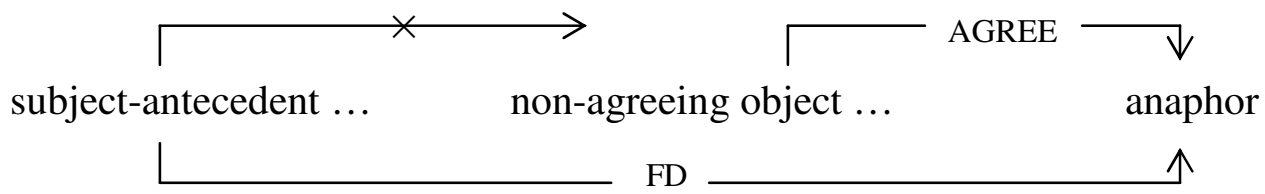

\section{Conclusion}

This paper provides a definition of SUBJECT in terms of functional dependencies in the spirit of the Minimalist Program. I have argued that functional dependency is an important theoretical device that follows directly from standard assumptions about phrase structure and syntactic relationships. Narrow Syntax utilizes this tool to determine domains of anaphors and to derive the subject-orientation of some types of anaphors. In addition to the theoretical argument, I have provided a variety of arguments for functional dependency from a variety of areas. First, functional dependencies were motivated on conceptual grounds, and it was shown that they follow from basic assumptions about phrase structure, agreement, etc. It was then demonstrated that functional dependencies could be used to define domains for local anaphors. The argument for functional dependencies was then extended to SOAs, where it was shown that functional dependencies provide a means of accounting for SOAs, and possibly a means to bring them within the fold of Binding Theory. Evidence for this analysis was drawn from the typological tendency for languages with object agreement not to have SOAs. This was reinforced by discussion of Italian, where binding of SOAs is determined by agreement. Finally, important evidence for the functional dependency approach was given from Icelandic quirky case constructions. The functional dependency approach predicts that quirky-case-marked DPs must agree with the verb. This prediction was proved correct. Ultimately, functional dependency may offer ways of explaining other types of subject orientation (e.g. subject-oriented PRO, subject-oriented adverbs, etc.), and may offer the prospect of unifying different types of SUBJECT with a single characteristic: grammatical SUBJECTs all functionally determine their sisters.

\section{Notes}

1. I would like to thank the audiences at SAALA 2006 and SICOL 2006 for their input. In particular, I would like to thank Joan Maling, Georges Rebuschi, Luis Vicente, Aniko Liptak, and Jie Huang for their data, insight, discussion, and suggestions. All remaining errors are my own. This paper is an extension of the paper presented at SICOL 2006, 
and develops the questions of binding domains and Icelandic anaphors, which could not be developed in the earlier paper.

2. I distinguish here between "subject" and SUBJECT, the former being a specific instantiation (limited to overt XPs in finite clauses) of the latter. The notion of SUBJECT covers instances which traditional subjecthood does not, e.g. possessors, PRO, etc.

3. The Incredible Hulk is the alter ego of Dr. Robert Bruce Banner.

4. It is also not immediately clear why SpecDP (the location of possessors) should be analogous to SpecTP, as at a feature level $\mathrm{T}$ and $\mathrm{N}$ have little in common.

5. The precise $\phi$ features will become apparent in section 6.3.1, where it will be shown that long-distance anaphors have person features, but lack additional $\phi$ features. Similarly, this paper will make clear the kind of command relation which is envisaged.

6. Actually, a so-called partial ordering with only two elements arguably constitutes a total ordering.

7. A formal definition is as follows: a relation $R$ satisfies functional dependency $\mathrm{X} \rightarrow \mathrm{Y}$ if, for every pair $r 1, r 2$ of tuples of $R$, if $r 1[\mathrm{X}]=r 2[\mathrm{X}]$, then $r 1[\mathrm{Y}]=r 2[\mathrm{Y}]$ (Sagiv et al. 1981: 437). In this paper, functional dependencies will be represented by arrows, e.g. $\mathrm{X} \rightarrow \mathrm{Y}$.

8. Space prohibits a formal proof that syntactic relations such as selection and AGREE instantiate functional dependencies. A formal proof would have to show that these relations are at least reflexive, transitive, and antisymmetric. A stronger hypothesis is that at least selection and AGREE are irreflexive, transitive, and antisymmetric, and thus instantiate strict partial ordering.

9. I wish to thank an anonymous reviewer for pointing this out. Strictly speaking, under the strongest version of my proposal, the tree in (11) could be redrawn with $\phi$ features projecting; this would retain the idea that the functional dependencies can be read off the tree structure. $[\mathrm{Agr} / \phi \ldots[\mathrm{TP} \ldots[\mathrm{T} \ldots]]]$ The result shows an agreement projection above $\mathrm{T}$, a structure which is fairly standard.

10. Note that I am not arguing that all functional dependencies represent phase structure clearly linguistic structures are subject to additional constraints that set theory is not. However, the utilization of functional dependencies is a useful tool to represent phrase structures and to provide additional insights.

11. I do not use AgrO (object agreement) projections, as there is a movement away from agreement projections in recent work, where it is assumed that $v$ assigns accusative case 
to the DP object. I have not represented this relationship for the sake of simplicity. However, nothing hinges on this, and one could also represent the DP object adjoined to $v \mathrm{P}$, where $v \rightarrow \mathrm{DP}$.

12. Note that this is not the same as saying the subject DP selects T. Rather, a subset of the features of the DP functionally determine a subset of features on T. Thus, by virtue of AGREE (i.e. not by virtue of selection), a functional dependency exists such that $\mathrm{DP} \rightarrow \mathrm{T}$.

13. I am aware that this argument is something of a straw man. Traditional binding theory might simply counter by saying that a binding domain is determined by the presence of a subject and not the presence of a subject position. However, this merely emphasizes that there is something about subjects that triggers domains - there is still no indication as to what that something might be.

14. Equally seriously, subjects are obligatory in clauses but are seemingly optional in DPs at least in English (i.e. the EPP, a putatively central feature of subjects, is not active inside English DPs).

15. I thank Jie Huang, a 28-year old male linguistics student who grew up in Qingdao, for his Mandarin judgements. I assume the Chinese examples quoted by Hellan (1991) to refer to Mandarin Chinese. All examples from my own informant are Mandarin.

16. There are, however, differences between the SOA phenomena in these languages. Cf. section 6.2.

17. A higher subject can only bind an LDA if the lower subject agrees in person features (cf. also Huang and Tang 1991; Cole and Hermon).

18. I do not want to justify the relative merits of this approach, merely to describe it.

19. But see Hellan (1991) for other possibilities.

20. There are a few instances where an element can FD-command something without it Ccommanding it, depending on one's notion of C-command. It is not clear to me that these instances actually ever occur in natural language, so in practice, it may be the case that FD-command is a subset of C-command. However, until this is demonstrated, I will assume that they are distinct.

21. In fact, given my argument that agreement can constitute a functional dependency, this claim is consistent with the assumption that anaphors have uninterpretable $\phi$ features which must be checked. The difference between AGREE (technically defined in terms of C-command) and functional dependency, is that only the subject's features functionally 
determine the anaphor, whereas it is conceivable that any intervening DP could AGREE with it.

22. Parameterization implies the existence of a feature with the value [+bound by functional dependency] and another feature with the value [+bound by C-command].

23. Supporting evidence for this intuition is that, while the Icelandic and Mandarin Chinese data show person features, and indirectly animacy, to be significant, Hungarian data show that at least some agreement features (e.g. definiteness features) are less important. Consider: Az ikrekfeljelentették Bélát egymásnak

the twins reported-3PL.DEF Bélát-ACC each.other-DAT

"The twins reported Béla to themselves"

In this example, object agreement occurs in terms of definiteness. However, AgrO does not delimit a domain for binding of ordinary anaphors; if it did, then the subject would be unable to bind the anaphor. This suggests that a full characterization of binding domains awaits further investigation. Sufficient for the moment is the fact that binding domains can be defined in terms of functional dependency.

24. PRO, if it is a true SUBJECT, must agree with $\mathrm{T}$ in terms of at least one feature. Number would seem to be the bare minimum type of agreement that can occur, as unlike person, it has clear semantic content. The issue of person is less clear (cf. section 6.3.2).

25. Note that this proposal does not necessarily derive all the characteristics of SOAs in (21). These await a fully fledged theory of SOAs, which is beyond the scope of this paper, which must necessarily restrict itself to the notion of SUBJECT.

26. I use the Reichenbachian notation provided by Giorgi and Pianesi (1997), where [S-R] (Speech Time precedes Reference Time), [R-S] (Reference Time precedes Speech Time) and [S,R] (Speech Time and Reference Time are unspecified in relation to each other).

27. An anonymous reviewer points out that it is potentially problematic for my account that, under some Minimalist accounts, abstract AGREE occurs between the object and $v$. It is true that $v$ assigns Case to the syntactic object via AGREE in order to account for Burzio's generalization. However, this is a functional dependency of the type $v \rightarrow \mathrm{DP}$ (not $\mathrm{DP} \rightarrow v$ ). Thus, it is not the case that $v$ assigning case to the object results in a situation where the DP object defines a binding domain. There is no evidence of the converse, where the DP object checks $\phi$ features on $v$. Even if $v$ were to have $u \phi$ features, then it would always be the case that the subject DP in SpecvP would be "closer" than the 
object DP - thus it would simply not be possible for the object DP to check $u \phi$ features on $v$, thereby creating a binding domain.

28. Czech also has similar constructions (Toman 1991).

29. An anonymous reviewer asks whether the sisterhood condition could not be weakened to a C-command condition, suggesting that if small clauses have heads, then this is independently necessary. In fact, the functional dependency approach does not prevent the possibility of the existence of small clause heads, as the $v$ head of a small clause must ultimately have a subject where $\mathrm{DP} \rightarrow v$ (or else there is no rationale for calling it a "small clause"). The DP would then transitively functionally determine everything in the complement of the small clause head. Equally, however, the functional dependency approach does not require the existence of a small clause head at all, as a functional dependency can be established directly between the DP and the AP complement if necessary. I am aware, though, that this runs against current conceptions of phrase structure.

30. It might be claimed that in (41b) a PP is a binding domain, and thus the reflexive in the PP cannot be bound from outside the domain. While this may be relevant for local anaphors, subject-oriented anaphors can by definition be bound from outside a local domain. Thus, the argument against $\mathrm{C}$-command cannot be evaded in this fashion.

31. Abstracting away from instances when non-human and non-animate objects are imbued with the human-like qualities of comprehension, e.g. in fairy-tale contexts.

32. In fact, this sheds light on why so many languages with SOAs also have logophors (cf. Table 1). Logophors are also oriented towards speaker perspective (Hellan 1991). Thus, there is a similarity between SOAs and logophors generally. The key difference is that logophors are subject to a pragmatic construal of (speaker) perspective, whereas syntactic SOAs are subject to the grammaticalization of that perspective, namely person features. An interesting question for future research would be to ascertain whether there is a diachronic grammaticalization cline between discourse logophors and syntactically bound SOAs.

33. Other means of identifying functional dependencies exist. For instance, if nominative case on DPs is uT on D, as proposed by Pesetsky and Torrego (2001), then there is a functional dependency such that $\mathrm{T} \rightarrow \mathrm{D}$. Similarly, in Icelandic quirky-case constructions, linguistics can identify a functional dependency even in the absence of agreement. 
34. Obviously there is no problem if there is the true subject of the sentence but also an overt manifestation of the moved, formal features of the associate.

35. Note that the Icelandic quirky-case constructions do exhibit an underlying AGREE relationship, and thus cannot be used to rule out the possibility of AGREE being the key characteristic of subjecthood.

36. Another reason against AGREE is that it is limited within phases. Thus, it is not possible for an antecedent to agree at long distance, across a phase boundary, with a reflexive. On the other hand, because functional dependencies are transitive, they can be computed at any distance, regardless of whether a phase-boundary intervenes or not.

\section{References}

Amiridze, N. 2006. Reflexivization Strategies in Georgian. Doctoral thesis, Utrecht University.

Armstrong, W. 1974. Dependency structures of database relationships. Proceedings of IFIP $74,580-583$.

Baker, M. 1996. The Polysynthesis Parameter. Oxford: Oxford University Press.

Baker, M. 2003. The natures of nonconfigurationality. In M. Baltin and C. Collins (eds). Handbook of Contemporary Syntactic Theory. Oxford: Blackwell. pp. 407-438.

Beeri, C., R. Fagin, and J. Howard. 1977. A complete axiomatization for functional and multivalued dependencies in database relations. In Proceedings of ACM-SIGMOD International Conference on Management of Data. Toronto.

Boeckx, C. 2000a. EPP eliminated. Manuscript. University of Connecticut.http://www.sinc. sunysb.edu/Clubs/nels/jbailyn/eppeliminated.pdf.

Boeckx, C. 2000b. Quirky agreement. Studia Linguistica 54, 354-380.

Bonet, E. 1994. The person-case constraint: A morphological approach. In H. Harley and C. Phillips (eds). The Morphosyntax Connection, MIT Working Papers in Linguistics 22: $33-52$.

Chomsky, N. 1981. Lectures in Government and Binding. Dordrecht: Foris.

Chomsky, N. 1995a. The Minimalist Program. Cambridge: MIT Press.

Chomsky, N. 1995b. Bare Phrase Structure. In G. Webelhuth (ed). Government and Binding theory and the Minimalist Program. Cambridge: Basil Blackwell. pp. 383-439.

Chomsky, N. 2000. Minimalist inquiries: The framework. In R. Martin, D. Michaels, and J. Uriagereka (eds). Step by Step. Cambridge: MIT Press. pp. 89-155. 
Codd, E. F. 1970. A relational model of data for large shared data banks. Communications of the ACM 13, 377-387. http://dblp.unitrier.de/db/journals/cacm/Codd70.html. [Also published in M. Stonebraker and Morgan-Kaufmann. 1988. Readings in Database Systems. pp. 5-15.

Cole, P. and G. Hermon. 2005. The typology of Malay reflexives. Lingua 115: 627-644.

Cole, P. Hermon, G., Sung, L.-M., 1990. Principles and parameters of long-distance reflexives. Linguistic Inquiry 21, 1-22.

Cole, P., G. Hermon, and L.M. Sung. 1993. Feature percolation. Journal of East Asian Linguistics 2: 91-118.

Cowper, E. 2005. The geometry of interpretable features: INFL in English and Spanish. Language 81: 10-46.

De Vos, M. 2006. Subject orientated anaphors and agreement. Paper presented at the LSSA/SAALA Annual Conference, University of Kwa-Zulu Natal, Durban.

De Vos, M. 2006. SUBJECTHOOD and phrase structure: Evidence from long-distance anaphora. In Proceedings of SICOL 2006, Linguistic Society of Korea, Seoul.

Devlin, K. 1993. The joy of sets: Fundamentals of contemporary set theory. New York: Springer.

Dutka, A. and H. Hanson. 1989. Fundamentals of data normalization. Reading: AddisonWesley Publishing Company.

Everaert, M. 1991. Contextual determination of the anaphor/pronominal distinction. In J. Koster amd E. Reuland. (eds). Long-Distance Anaphora. Cambridge: Cambridge University Press. pp. 77-118.

Everaert, M. 2001. Paradigmatic restrictions on anaphors. In K. Megerdoomian and L.A. Barel (eds). WCCFL 20 Proceedings. Somerville: Cascadilla Press.

Gill, K.H. 1999. The long-distance anaphora conspiracy: The case of Korean. University of Pennsylvania Working Papers in Linguistics 6: 171-183.

Giorgi, A. 1991. Prepositions, binding and $\theta$-marking. In J. Koster and E. Reuland (eds). Long-Distance Anaphora. Cambridge: Cambridge University Press. pp. 185-208.

Giorgi, A., Pianesi, P. 1997. Tense and Aspect: From Semantics to Morphosyntax. New York: Oxford University Press.

Halmos, R. 1960. Naive Set Theory. Princeton: Van Norstrand. 
Harbert, W. 1995. Binding theory, control and pro. In G. Webelhuth (ed.) Government and Binding Theory and the Minimalist Program. Cambridge MA: Blackwell publishing. pp. 177-240.

Hellan, L. 1991. Containment and connectedness anaphors. In J. Koster and E. Reuland (eds). Long-Distance Anaphora. Cambridge: Cambridge University Press. pp. 27-48.

Huang, C-T. J. and C-C. J. Tang. 1991. The local nature of the long-distance reflexive in Chinese. In J. Koster and E. Reuland (eds). Long-Distance Anaphora. Cambridge: Cambridge University Press. pp. 263-282.

Huang, Y. 1996. A note on the head-movement analysis of long-distance reflexives. Linguistics 34: 833-840.

Kennedy, C. and J. Lidz. 2001. A (covert) long distance anaphor in English. In K. Megerdoomian and L. Bar-el (eds). WCCFL 20 Proceedings. Somerville: Cascadilla Press.

Koster, J. 1985. Reflexives in Dutch. In J. Guéron, H. Obenauer, and J-Y. Pollock (eds). Grammatical Representation. Dordrecht: Foris. pp. 141-168.

Koster, J. and E. Reuland. 1991. Long-distance anaphora: An overview. In J. Koster and E. Reuland (eds). Long-Distance Anaphora. Cambridge: Cambridge University Press. pp. $1-26$.

Larson, R. 1988. On the Double Object Construction. Linguistic Inquiry 19: 335-391.

Leland, G. and J. Kornfilt. 1981. Finiteness and boundedness in Turkish. In F. Heny (ed). Binding and Filtering. Cambridge: MIT Press. pp. 105-127.

Levinson, S. 2000. Presumptive Meanings: The Theory of Generalized Conversational Implicatures. Cambridge: MIT Press.

Maling, J. 1984. Non-clause-bounded reflexives in Icelandic. Linguistics and Philosophy 7: 211-241.

Martin, R. 1999. Case, the extended projection principle and minimalism. In S. Epstein and N. Hornstein (eds). Working Minimalism. Cambridge: MIT Press. pp. 1-25.

Pesetsky, D. and E. Torrego. 2001. T-to-C movement: Causes and consequences. In M. Kenstowicz (ed). Ken Hale: A Life in Language. Cambridge: MIT Press. pp. 355-426.

Pica, P. 1986. On the nature of the reflexivization cycle. In J. McDonough and B. Plunkett (eds). Proceedings of NELS 17, GLSA. Amherst: University of Massachusetts. 
Pica, P. 1991. On the interaction between antecedent government and binding: The case of long-distance reflexivization. In J. Koster and E. Reuland (eds). Long-Distance Anaphora. Cambridge: Cambridge University Press. pp. 119-136.

Reinhart, T. and E. Reuland. 1991. Anaphors and logophors: An argument structure perspective. In J. Koster and E. Reuland (eds). Long-Distance Anaphora. Cambridge: Cambridge University Press. pp. 283-322.

Sagiv, Y., C. Delobel, D. Stott Parker, and R. Fagin. 1981. An equivalence between relational database dependencies and a fragment of propositional logic. Journal of the Association for Computing Machinery 28: 435-453.

Sells, P. 1987. Aspects of logophoricity. Linguistic Inquiry 18: 445-481.

Sigurðsson, H. 1990. Long-distance reflexives and moods in Icelandic. Syntax and semantics 24: 309-346.

Sigurðsson, H. 1996. Icelandic finite verb agreement. Working papers in Scandinavian syntax 57: $1-46$.

Stowell, T. 1982. The tense of infinitives. Linguistic Inquiry 13: 561-570.

Szabolcsi, A. 1983. The Possessor that Ran Away from Home. The Linguistic Review 3: 89102.

Szabolcsi, A. 1994. The noun phrase. In F. Kiefer and K. Kiss (eds). The Syntactic Structure of Hungarian. No. 27 in Syntax and Semantics. San Diego: Academic Press. pp. 179275.

Taraldsen, T. 1995. On agreement and nominative objects in Icelandicc. In H. Haider, S. Olsen, and S. Vikner (eds). Studies in Comparative Germanic Syntax. Dordrecht: Kluwer. pp. 307-327.

Thráinsson, H. 1991. Long-distance reflexives and the typology of NPs. In J. Koster and E. Reuland (eds). Long-Distance Anaphora. Cambridge: Cambridge University Press. pp. 49-76.

Toman, J. 1991. Anaphors in binary trees: An analysis of Czech reflexives. In J. Koster and E. Reuland (eds). Long-Distance Anaphora. Cambridge: Cambridge University Press. pp. 151-170.

Wurmbrand, S. 2001. West germanic verb clusters: The empirical domain. Unpublished manuscript.

Zaenen, A., J. Maling, and H. Thráinsson, H. 1985. Case and grammatical functions: The Icelandic passive. Natural Language and Linguistic Theory 3: 441-483. 